Session 2793

\title{
Using the Fundamentals Exam as a Legislative Performance Indicator
}

\author{
Charles D. Turner, \\ Department of Civil Engineering, \\ Darrell Schroder, \\ Assistant Dean, College of Engineering, \\ Anthony Tarquin, \\ Department of Civil Engineering \\ William L. Craver, Department of Mechanical \& Industrial Engineering \\ University of Texas at El Paso
}

\begin{abstract}
The faculty of the College of Engineering at The University of Texas at El Paso (UTEP) decided in 2000 to require all students in Civil Engineering, Mechanical Engineering, Metallurgical and Materials Engineering and Industrial Engineering to take and pass the National Council of Examiners for Engineering and Surveyors (NCEES) Fundamentals Exam (FE) before graduating. Additionally, passage of a competency examination is required for all students in these departments in order to enroll in upper division classes. This paper reports on the results of these actions.
\end{abstract}

The legislative budget committee in the State of Texas decided to require reporting of FE results for all University of Texas (UT) System schools offering engineering degrees in 1998. The stated purpose was that the results of the FE exam are to be used as a nationally normed assessment tool for UT System engineering school performance. The fear among some administrators is that the FE exam performance will be tied to funding of engineering programs at the various institutions. Anticipation of this future possibility led the faculty in the Department of Civil Engineering to require passage of the FE exam as an undergraduate degree requirement. The other departments followed suit. Since the ABET accreditation visit was scheduled for 2001, the FE exam was also adopted as an assessment tool. Quality control of students entering the upper division also became a concern because passage of the FE is tightly linked to performance in lower division coursework. Therefore, a competency exam for rising juniors was implemented as a quality control and assessment measure. An information program to inform students of the new measures and two sets of review opportunities were developed to ensure student success on the FE exam. Quantitative results of these new requirements and the impact on student attitudes and performance and the feed back loop to course modifications are reviewed.

\section{State of Texas FE Performance Requirement}

The State of Texas has spent many years developing evaluation criteria for its various agencies and components. Texas public institutions with engineering programs are now required to report 
pass rates achieved by their graduates on the Fundamentals of Engineering examination. For example, the state mandated goal at UTEP is a pass rate of $80 \%$. If the yearly pass rate for this institution falls below $75 \%$, the chief academic officer of the institution is required to submit an explanation to the Legislative Budget Board of the state. The use of the Fundamentals Exam for assessment was discussed in the literature by LeFevere, Steadman and White (1999). Since the State of Texas is using the FE as an assessment tool, UTEP must do so as well.

\section{Competency Exam}

The competency exam was created in an effort to assess the knowledge students gained in their lower division coursework and as an assessment tool for UTEP's ABET visit in the fall of 2001. The FE exam was being considered as an assessment tool for measuring performance but the faculty wanted the outcome to be as positive as possible. One way of accomplishing this was to require students entering the upper division to pass an exam based on coursework in the lower division. This type of exam is sometimes termed a "rising junior" exam. All students are required to take and pass the exam prior to registering for upper division coursework. This includes both transfer and UTEP students. The exam is designed similar to the morning session of the FE exam that tests knowledge of lower division coursework.

A small interdepartmental committee designed the exam. Present versions of the exam consist of 70 questions from all areas covered on the FE with the exception of Computer Science. The number of questions in any given area is roughly proportional to the number of questions in the same area on the FE. The areas covered include statics, dynamics, mechanics of materials, math, engineering economics, chemistry, materials science, thermodynamics, fluid mechanics and electrical. There are several versions of the exam. The students are given two opportunities to take the exam during the semester prior to registration for upper division coursework. If the student fails to pass it on the first attempt, he/she can take the exam a second time the following week. If the student fails the exam a second time, he/she is counseled on remedial measures. The results from 354 attempts are shown in Figure 1.

Grades for the competency exam in Figure 1 are distributed as shown in Series 1 data and the cumulative frequency of those grades is shown in the Series 2 curve.

Pass and fail rates are shown in Figure2. A score of about 49 on the competency exam is considered passing depending on the grade distribution. The authors have determined that a student must answer approximately 50 percent of problems correctly on the NCEES FE exam in order to receive a passing score. Therefore, a similar score on the competency exam was thought to be a good starting point. The mean score for all competency exams administered is 49.4 percent. Using this passing grade criterion, 230 students passed on the first try. Another 31 of 68 students passed on the second try. A few took the exam as many as four times. The mean for all students passing the exam is 56 percent. When repeat exams are removed, there are 261 first attempts at the exam. The passing percentage on the first try was 78.7 percent (230 of 292), with 89.4 percent passing (261 of 292) after two attempts. This means that 89.4 percent of the students taking the exam have been successful and moved into the upper division of their respective programs. The other 10.6 percent are still in the recirculation group or they transferred to other departments.

"Proceedings of the 2003 American Society for Engineering Education Annual conference \& Exposition Copyright c 2003, American Society for Engineering Education" 


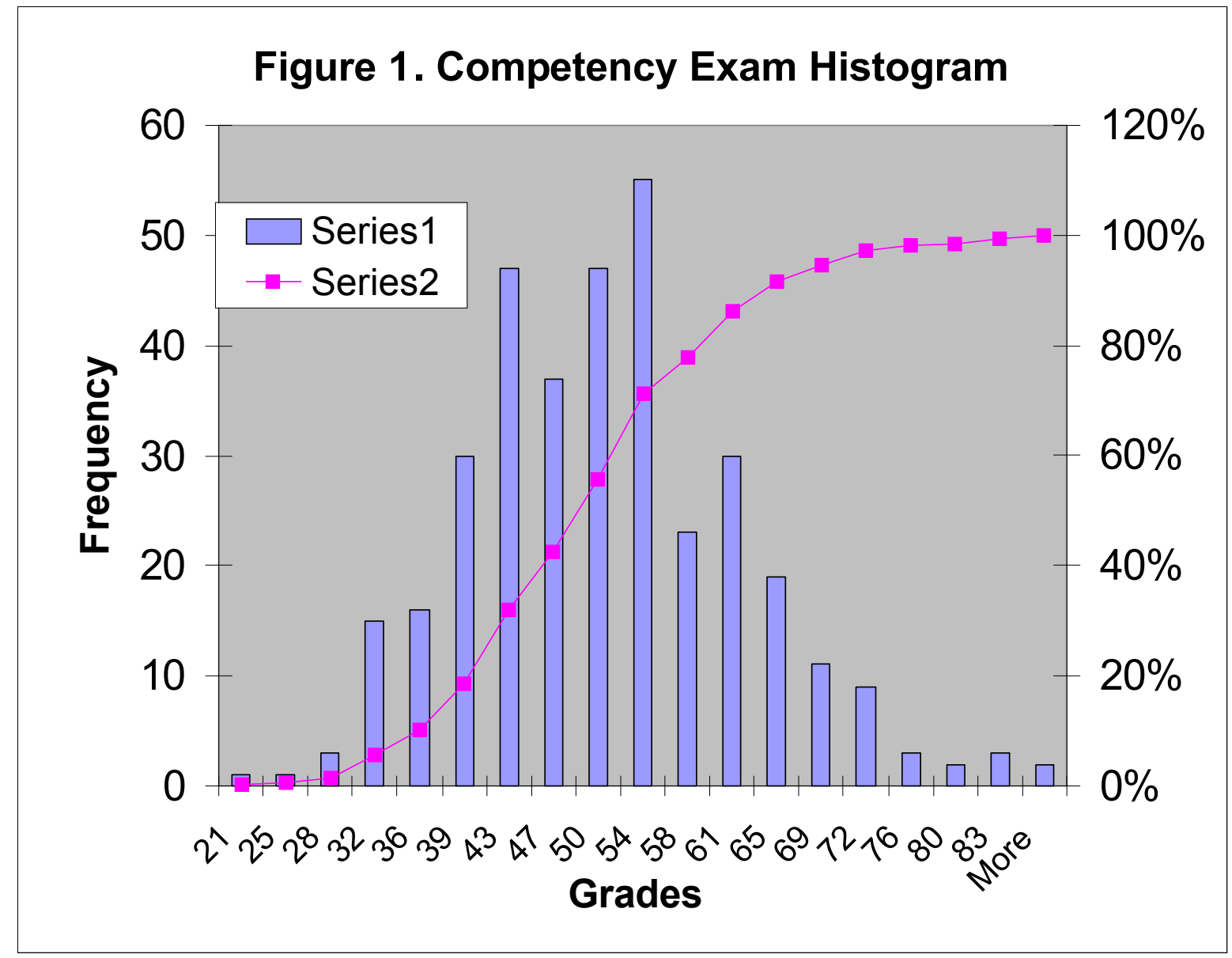

\section{Figure 2. Competency Exam Raw Scores}

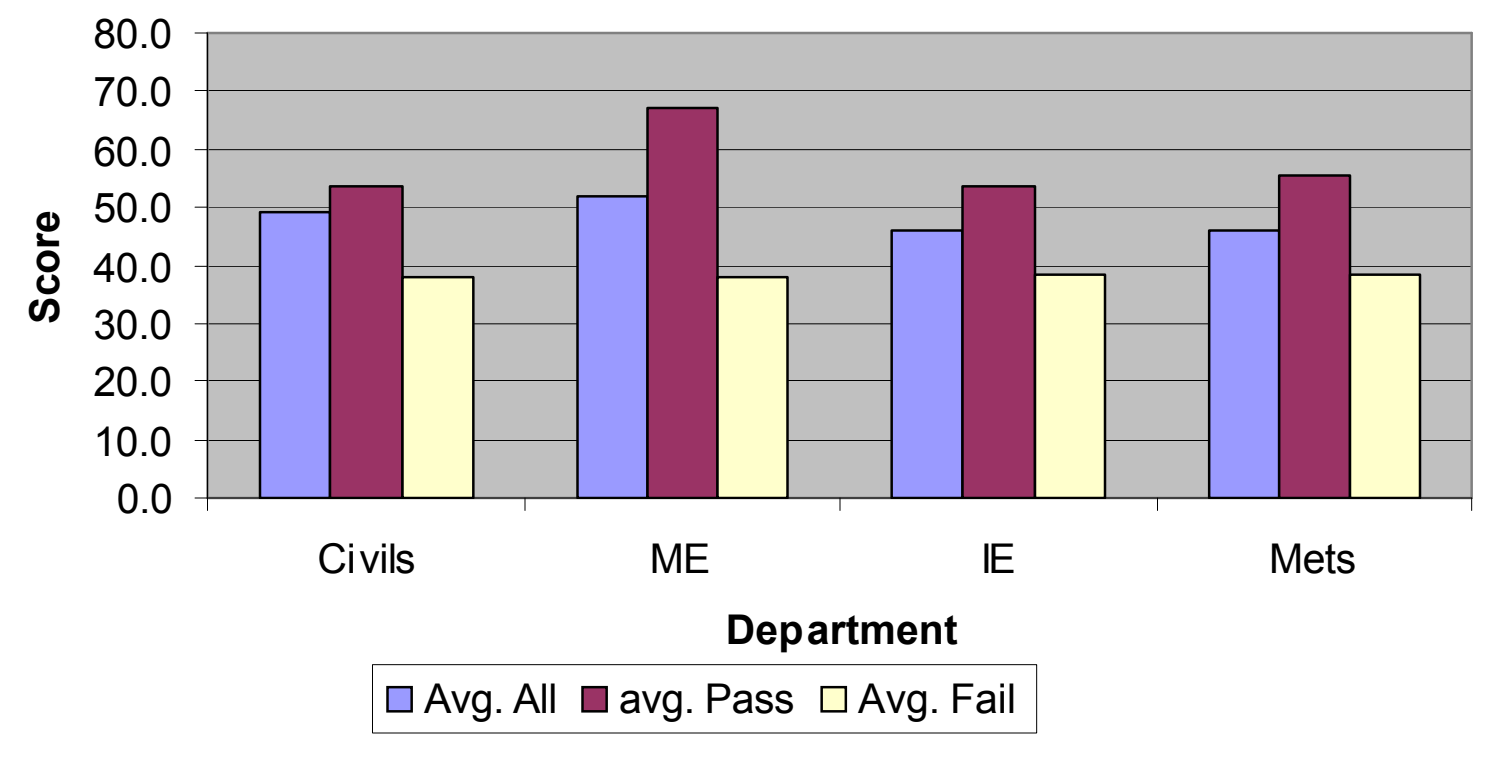




\section{FE Exam Preparation}

The College of Engineering, in cooperation with Professional and Continuing Education at UTEP, has developed a semester-long review course to facilitate preparation for the FE examination. The course meets for two three-hour review sessions each week. Virtually all of the subjects covered on the FE examination are reviewed. College of Engineering faculty teach the review. In most cases, the same faculty that teach the material in the normal curriculum also teach the review session.

The main problem with the review course is to ensure that students who need the review actually attend. The College has experimented with a variety of ways of ensuring that the review sessions are well attended. Innovative efforts have included paying the students $\$ 100$ for attending the review and passing the FE!

The most effective way found to date is to tie the FE review sessions to the Senior Professional Orientation (SPO) course. At the beginning of every semester, a few diagnostic exams are given as time allows. SPO meets once a week on Fridays. Each Friday an exam is given over the material covered in the previous 6 hours (two sessions) of the Continuing Education review course. The same questions are used on both the diagnostic exam and the respective Friday exams, which allows a measure of the effectiveness of the review sessions. The scores on the Friday exams also determine the grade the student will receive for the SPO class. Thus, we have some idea if the review sessions are helpful and the students are motivated to attend the Continuing Education sessions, at least concerning material with which they may not be totally familiar.

Most of the sessions of the Professional and Continuing Education short course are narrowed to topics that are known or likely to be covered on the FE exam. Likewise, the SPO examinations are similarly oriented. Spring 2001 was the first time that we have tried this exact motivational approach. Data to date suggests that the Continuing Education review improves the student performance on the FE by approximately 10 percent.

\section{Results}

Figure 3 is a plot of the grades made by students on the competency exam versus the grade made by the same student on the actual FE exam. Although the competency exam is designed to predict performance on only the morning portion of the FE exam, the figure shows that there is considerable correlation between the score a student gets on the competency exam (taken in the student's sophomore year) and the score the same student will get on the actual FE exam (taken two years later), even though the competency exam is equivalent to only one-half of the actual FE exam. The graph also shows that only three students who got a grade of $49 \%$ or higher on the competency exam failed the FE exam (i.e. got a grade less than 70\%), and two of those three students failed the competency exam the first time they attempted it. This is obviously important for identifying students "at risk".

Figure 4 shows the overall scores on the competency exam versus the results on the FE exam by subject area. Nearly all of the competency exam scores are lower than those of the FE exam. His is because most of the students who take the competency exam have not completed all of the

"Proceedings of the 2003 American Society for Engineering Education Annual conference \& Exposition Copyright c 2003, American Society for Engineering Education" 
courses that are covered. Nevertheless, the graph shows that there is generally a good correlation between the competency exam results and the FE scores. This represents a tremendous tool for not only predicting performance on the FE exam, but also for determining which courses need to be improved and for evaluating the effect of CQI-induced course changes on actual student performance.

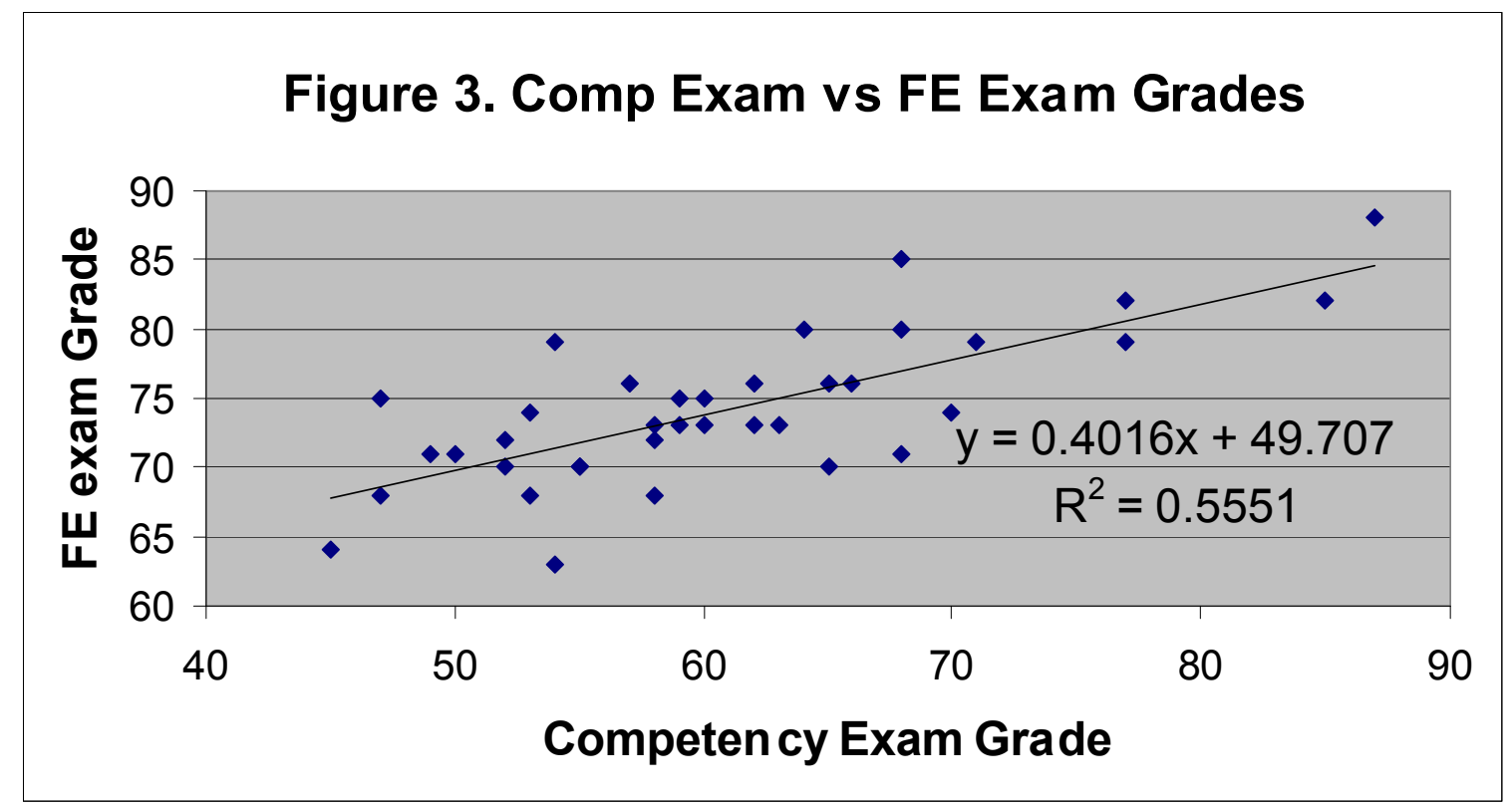

Figure 4. FE/Competency Exam Comparison

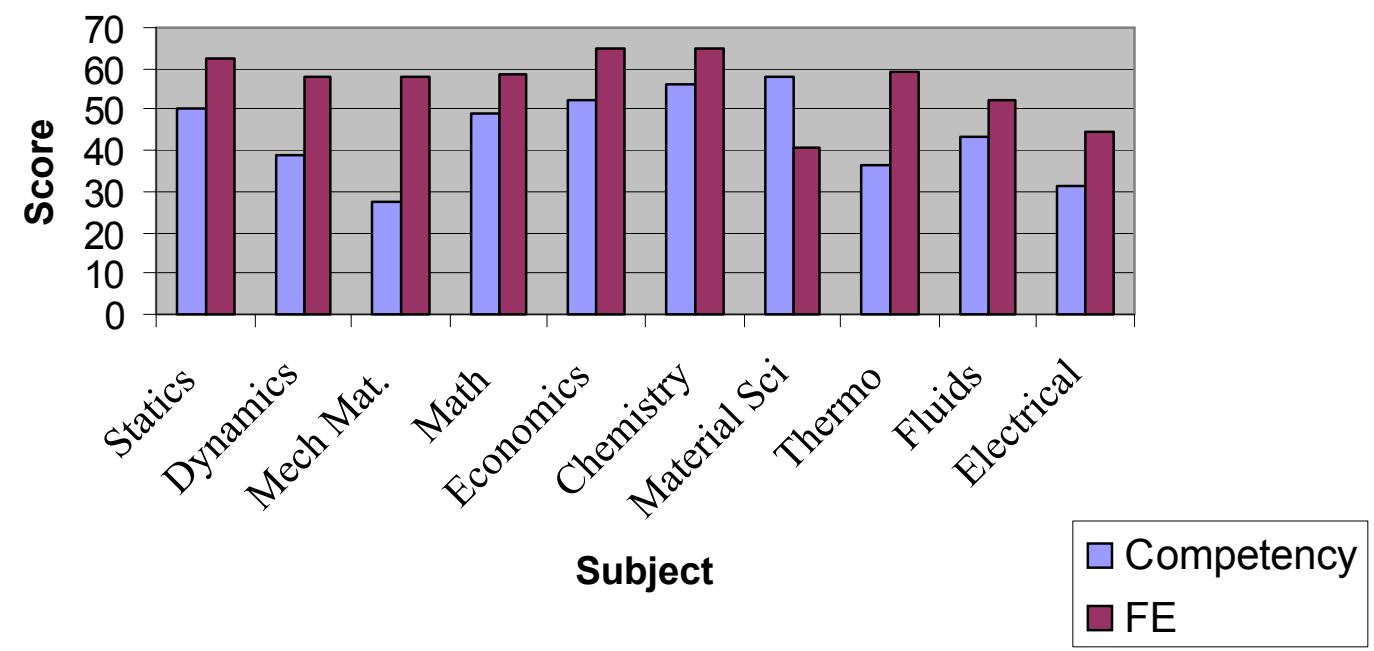


Table 1 below shows passing rates for the last seven years (1996-2002). For this table the passing rate is defined as the number of prospective graduates passing the FE exam divided by the number of perspective graduates attempting the exam. It should be noted that the Texas State Board of Engineering Examiners uses a slightly different reporting method. The State Board pass rate is computed by dividing the number of graduates passing the exam by the number of graduates taking it.

Table 1. UTEP Passing Rates for College of Engineering Students Attempting the Exam

\begin{tabular}{|c|c|}
\hline Year & Percent Passing \\
\hline 1996 & $73 \%$ \\
\hline 1997 & $77 \%$ \\
\hline 1998 & $69 \%$ \\
\hline 1999 & $74 \%$ \\
\hline 2000 & $82 \%$ \\
\hline 2001 & $69 \%$ \\
\hline 2002 & $74 \%$ \\
\hline
\end{tabular}

Beginning in the fall 2001, taking and passing the FE exam became a course requirement in the respective senior professional orientation courses taken by all Mechanical, Industrial, and Civil engineering students. Therefore, the pass rate for all graduating engineers has become 100 percent. Currently, two civil engineering students and four or five students from the other disciplines have not graduated because of FE exam passage requirement.

\section{Conclusions}

Requiring passage of the FE exam for graduation has changed the attitude of students taking the exam. Previously, many students had a very relaxed attitude towards the FE exam and their passing rate reflected this attitude. Now, all students take the exam seriously and most have accepted the requirement with little objection. This qualitative assessment is based on specific questions asked by department chairs during exit interviews with graduating seniors. Acceptance has been widespread because of (1) efforts made by the departments to inform the students of the reasons for the FE passage requirement, (2) provision of review courses to assist the students and (3) counseling of students who have had difficulty passing the exam.

Analysis of data from both the competency exam and the FE is allowing the departments to assess performance in terms of course modifications needed to enhance student performance. This feedback loop is critical to continuous quality improvement. Questions still remain as to the impact on retention of students in departments that require passage of both the competency exam and the FE. Analysis of this issue can only be done by reviewing individual student records in an attempt to follow student choices if they fail to pass either exam. To date, however, only one student who failed the competency exam four times is known to have changed to and engineering 
department that did not require passage of either one.

\section{References}

W. LeFevere, J.W. Smith, J.W. Steadman, K.R. White, Using the Fundamentals of Engineering Examination to Assess Academic Programs, NCEES, 1999.

\section{Biographical Information}

CHARLES TURNER is a Professor of Civil Engineering. He has been at UTEP for 12 years. His primary fields of research are water resources of the Rio Grande and handling of concentrate from desalination processes. He is currently working on a desalination project in Ciudad Juarez and a water resources book on the Rio Grande.

DARRELL SCHRODER is a professor of Electrical Engineering and Assistant Dean for Undergraduate Students. His field of interest is student development and assessment. He is an adamant tinker and is constantly working with students on projects involving microprocessor applications.

ANTHONY TARQUIN is a Professor of Civil Engineering. He has been at UTEP for 30 years. His primary filed of research is water treatment and he is currently working with the El Paso Water Utility on disinfection and desalination projects.

WILLIAM L. CRAVER is a professor in the Department of Mechanical \& Industrial Engineering. He has been at UTEP for 30 years. His research interests include engineering mechanics, experimental stress analysis, vibrations, and noise control.

"Proceedings of the 2003 American Society for Engineering Education Annual conference \& Exposition Copyright c 2003, American Society for Engineering Education" 